\title{
SISTEM PENERIMAAN CALON MAHASISWA BARU DENGAN MENGGUNAKAN APLIKASI LOGIKA FUZZY PADA MATLAB TOOLBOX
}

\author{
AISYAH AYU WULANDARI ${ }^{1}$, MIFTAKHUDIN YUSUF ${ }^{2}$, VI BAUTY RISKA UTAMI ${ }^{3}$, YOGA ADI PERMANA $^{4}$ \\ IT Telkom Purwokerto1234 \\ e-mail : 17101024@ittelkom-pwt.ac.id
}

\begin{abstract}
In this era, education is a crucial thing, one of which is a tertiary institution. At a tertiary institution to be able to enter one of the tertiary institutions, there is a process in it that contains a series of activities ranging from registration, selection based on standards made and acceptance. In this process, to facilitate a process in determining the prospective new students by the needs requires a long process and consideration for that, we need a system to facilitate the selection process. Fuzzy logic is a methodology of problem-solving control systems that can be implemented on a system. The application of the new student admission system modeling using independent lane logic applications. This modeling is used as a system to solve or simplify a problem. In making a system modeling, a method like the Mamdani method is needed. Mamdani method is often known as the max-min method. In the Mamdani method, there are several stages, namely determining the fuzzy set, the implication function implications, the composition of the rules, and defuzzication. In this modeling using a fuzzy set of Scholastic Potential Test (TPS) and Academic Competency Test (TKA) variables. The magnitude of the value of the two variables is very influential on the output results that determine whether the prospective new student is accepted, considered, or rejected. From the modeling of this system, it can be concluded that by making modeling of this system can simplify and shorten the selection process of new students just by filling in the input values in the modeling of the system and will get definite results.
\end{abstract}

Key Words : Fuzzy, Student, Mamdani

\begin{abstract}
ABSTRAK
Pada era saat ini Pendidikan menjadi suatu hal yang sangat penting salah satunya perguruan tinggi. Pada perguruan tinggi untuk bisa masuk di salah satu perguruan tinggi terdapat suatu proses di dalamnya yang berisi serangkaian kegiatan mulai dari pendaftaran, seleksi berdasarkan standar yang dibuat dan pernerimaan. Pada proses tersebut untuk memudahkan suatu proses dalam menentukan calon mahasiswa baru yang sesuai dengan kebutuhan memerlukan proses dan pertimbangan yang Panjang untuk itu diperlukan suatu sistem untuk mempermudah proses seleksi. Logika fuzzy merupakan suatu metodologi sistem kontrol pemecahan masalah yang dapat diimplementasikan pada sistem. Penerapan pemodelan sistem penerimaan calon mahasiswa baru jalur mandiri dengan menggunakan aplikasi logika fuzzy. Pemodelan ini digunakan sebagai sebuah sistem untuk menyelesaikan atau menyederhanakan suatu masalah. Dalam membuat suatu pemodelan sistem diperlukan sebuah metode seperti metode Mamdani. Metode Mamdani sering dikenal dengan metode max min. Pada metode Mamdani terdapet beberapa tahapan yaitu menentukan himpunan fuzzy, amplikasi fungsi implikasi, komposisi aturan dan defuzzikasi. Pada pemodelan ini menggunakan himpunan fuzzy dari variabel Test Potensi Skolastik (TPS) dan Tes Kompetensi Akademik (TKA). Besaran nilai dari kedua variabel tersebut sangat berpengaruh pada hasil output yang menentukan calon mahasiswa baru tersebut apakah diterima, dipertimbangkan atau ditolak. Dari pemodelan sistem ini dapat disimpulkan bahwa dengan membuat sebuah pemodelan sistem ini dapat mempermudah dan mempersingkat proses seleksi calon mahasiswa baru hanya dengan mengisi nilai input pada pemodelan sistem tersebut dan akan mendapat hasil yang pasti.
\end{abstract}

Kata Kunci: Fuzzy, Mahasiswa, Mamdani 


\section{PENDAHULUAN}

Pada era saat ini pendidikan salah satu hal yang sangat penting, perguruan tinggi merupakan salah satu tempat pendidikan dimana proses untuk masuk kedalamnya (menjadi mahasiswa). Informasi penerimaan mahasiswa baru merupakan suatu kegiatan yang rutin dilakukan setiap tahun, banyak jalur yang dapat digunakan oleh para siswa untuk masuk ke perguruan tinggi. Salah satu jalur yang digunakan yaitu jalur mandiri, jalur ini merupakan jalur yang dibuat oleh perguruan tinggi tersebut (sistem) untuk menseleksi calon mahasiswanya. Sistem yang digunakan pada jalur mandiri ini yaitu ujian tertulis yang terdiri dari banyak jenis soal. Untuk itu diperlukan satu aplikasi yang memudahkan untuk menentukan diterimanya calon mahasiswa pada perguruan tinggi. Pada penelitian ini, melakukan penerapan logika fuzzy pada penerimaan mahasiswa baru pada jalur mandiri.

Logika fuzzy suatu metodologi sistem kontrol pemecahan masalah yang dapat diimplementasikan pada sistem, baik sistem yang sederhana, kecil, sistem tertanam, sistem kontrol, multi channel. Selain dapat diterapkan pada sistem, logika fuzzy juga dapat diterapkan pada perangkat keras, perangkat lunak, maupun bagian dari kedua [1].

Batasan masalah penelitian ini menerapkan logika fuzzy pada variabel Tes Kompetensi Akademik dan Tes Potensi Skolastik dengan menggunakan metode mamdani. Metode mamdani atau biasa disebut dengan max-min merupakan metode yang diperkenalkan oleh Ebrahim Mamdani pada tahun 1975[2].

Penerapan pemodelan sistem penerimaan calon mahasiswa baru jalur mandiri dengan menggunakan aplikasi logika fuzzy pada software Matlab Toolbox. Permodelan ini digunakan sebagai sebuah sistem untuk menyelesaikan atau menyederhanakan suatu permasalahan. Dimana tujuan utama dari perancangan permodelan adalah supaya memudahkan user dalam membuat suatu keputusan sehingga penyelesaian dan hasil yang didapatkan secara mekanis cepat dan tepat.

\section{TINJAUAN PUSTAKA}

\section{Logika Fuzzy}

Ditinjau dari bahasa, logika berarti penaralan sedangkan fuzzy berarti samar, dengan kata lain logika fuzzy yaitu penalaran yang samar[3]. Dimana logika ini dapat bernilai true maupun false secara bersamaan[1]. Nilai true dan false ditentukan dari bobot keanggotaan yang dimilikinya. Nilai derajat keanggotaan logika fuzzy berbeda dengan nilai derajat keanggotaan logika digital, dimana pada derajat keanggotaan logika digital memiliki 0 atau 1 sedangkan pada logika fuzzy memiliki rentang antara 0 sampai 1 . Fungsi dari derajat keanggotaan ini adalah menjati suatu kerva yang memetakan titik-titik input data ke dalam nilai keanggotaannya[4].

Terdapat beberapa fungsi keanggotaan logika fuzzy, diantaranya[5] :

\section{Fungsi Keanggotaan Segitiga}

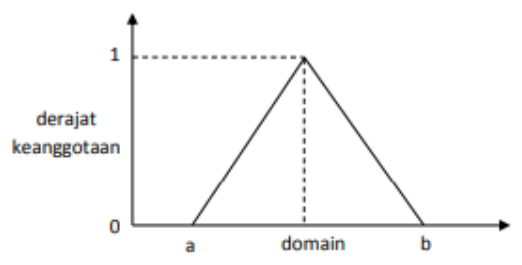

Gambar 1. Fungsi keanggotaan segitiga

$$
\mu[x]=\left\{\begin{array}{c}
0 ; x \leq a \text { atau } x \geq c \\
\frac{(x-a)}{(b-a)} a \leq x \leq b \\
\frac{(b-x)}{(c-b)} b \leq x \leq c
\end{array}\right.
$$

2. Fungsi Keanggotaan Trapesium

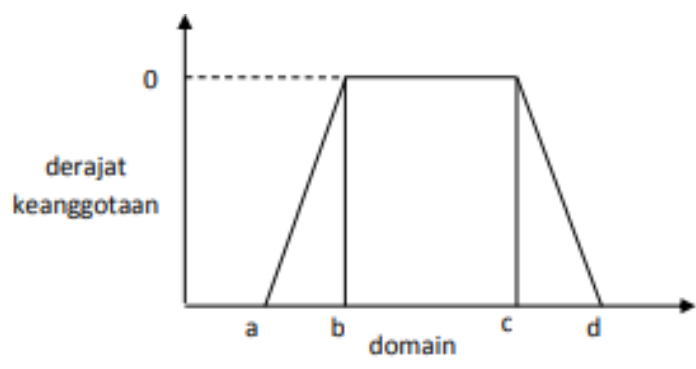

Gambar 2. Fungsi Keanggotaan Trapesium

$$
\mu[x]=\left\{\begin{array}{c}
0 ; x \leq a \text { atau } x \geq d \\
\frac{(x-a)}{(b-a)} ; a \leq x \leq b \\
1 ; b \leq x \leq c \\
\frac{(d-x)}{(d-c)} ; x \geq d
\end{array}\right.
$$

\section{Fungsi Keanggotaan Linier Naik}

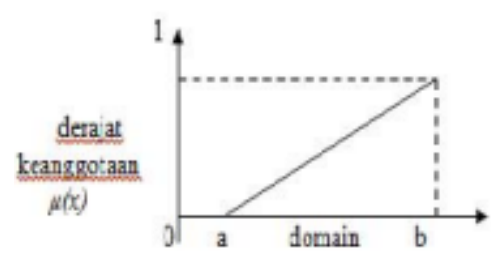

Gambar 3. Fungsi Keanggotaan Linier Naik 


$$
\mu[x]\left\{\begin{array}{c}
0 ; x \leq a \\
\frac{(x-a)}{(b-a) ; a} ; x \leq b \\
1 ; x \geq b
\end{array}\right.
$$

4. Fungsi Keanggotaan Linier Turun

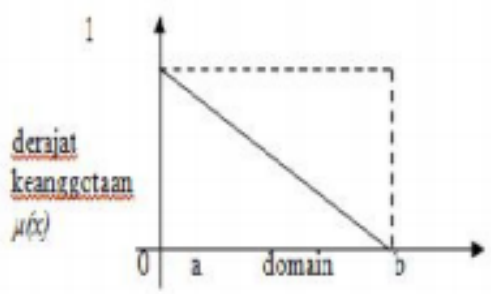

Gambar 4. Fungsi Keanggotaan Linier Turun

$$
\mu[x]=\left\{\begin{array}{c}
\frac{(b-x)}{(b-a)} ; a \leq x \leq b \\
0 ; x \geq b
\end{array}\right.
$$

\section{Metode Mamdani}

Pada metode mamdani untuk mendapat output harus melawati beberapa tahap [6], yaitu :

1. Pembentukan Himpunan Fuzzy

2. Aplikasi Fungsi Implikasi

3. Komponen Aturan

4. Penegasan (defuzzikasi)

\section{METODE}

Pada penelitian ini menggunakan metode mamdani, berikut pemodelan sistem dari logika fuzz.

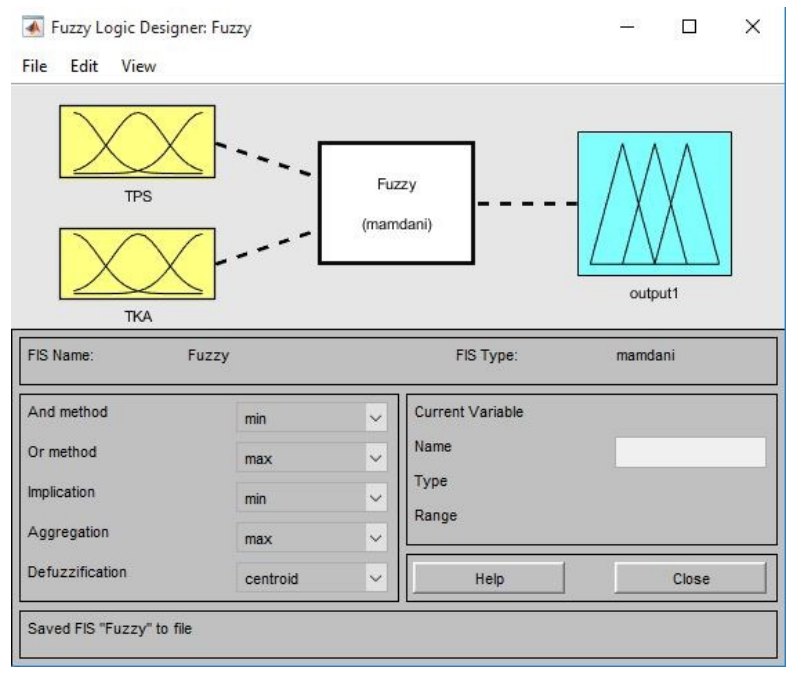

Gambar 5. Pemodelan sistem
Untuk tahapan pada penelitian ini sebagai berikut :

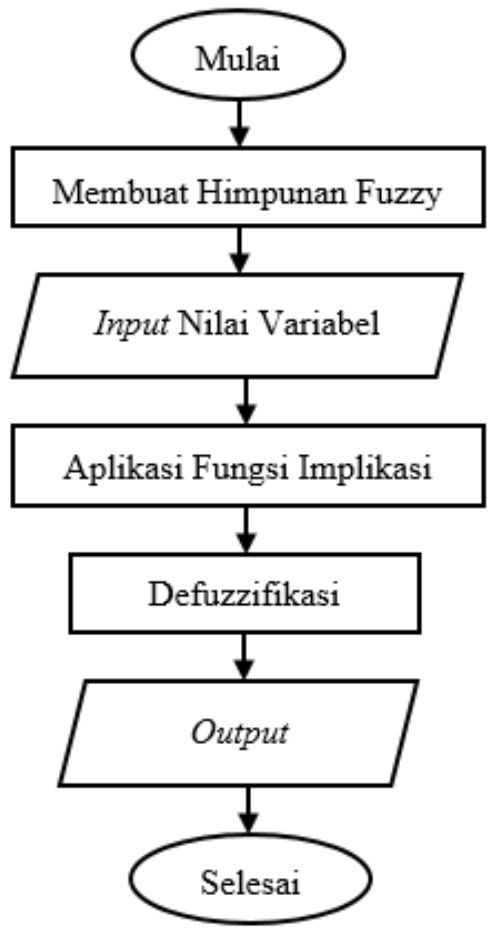

Gambar 6. Flowchart Penelitian

Tahapan penelitian ini dimulai dengan menentukan himpunan fuzzy dari variabel Tes Potensi Skolastik (TPS) dan Tes Kompetensi Akademik (TKA). Kemudian input nilai dari variabel, menentukan aplikasi fungsi implikasi dan membuat rule pada komposisi aturan. Setelah itu masuk defuzzifikasi.

\section{HASIL DAN PEMBAHASAN}

\section{Himpunan Fuzzy}

1. Himpunan fuzzy Tes Potensi Skolastik (TPS)

Himpunan fuzzy yang digunakan pada metode mamdani terdiri dari satu atau lebih himpunan fuzzy, berikut untuk himpunan fuzzy Tes Potensi Skolastik (TPS) :

Tabel 1. Himpunan fuzzy Tes Potensi Skolastik (TPS)

\begin{tabular}{|c|c|c|}
\hline No & Nilai & Status \\
\hline 1 & $0-500$ & Kurang \\
\hline 2 & $500-600$ & Cukup \\
\hline 3 & $600-1000$ & Baik \\
\hline
\end{tabular}




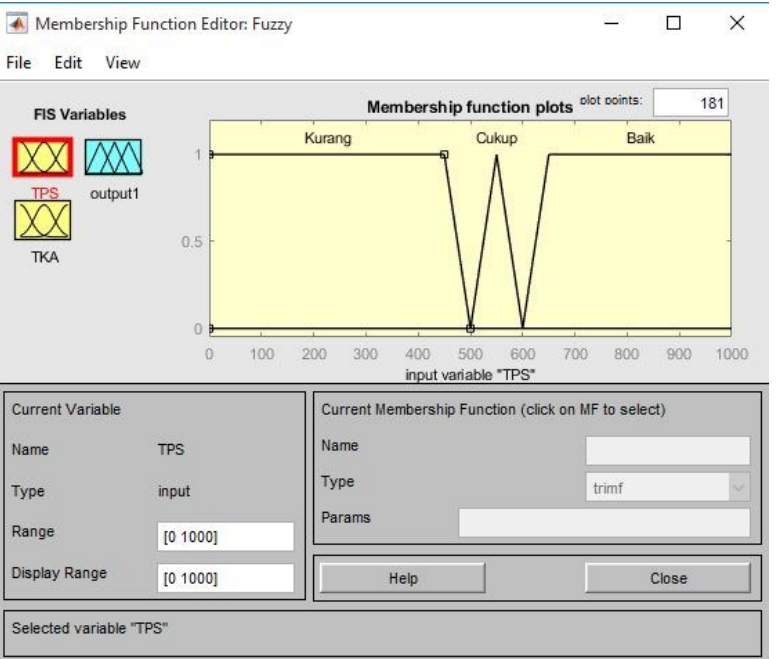

Gambar 7. Permodelan Tes TPS

$\mu$ Kurang $\left(x=\left\{\begin{array}{c}1 ; x \leq 450 \\ \frac{500-x}{50} ; 450 \leq x \leq 500 \\ 0 ; x \geq 500\end{array}\right.\right.$

$\mu$ Cukup $(x)=\left\{\begin{array}{c}1 ; x \leq 450 \text { atau } x \geq 600 \\ \frac{x-500}{50} ; 500 \leq x \leq 550 \\ \frac{600-x}{50} ; 550 \leq x \leq 600\end{array}\right.$

$\mu B$ aik $(x)=\left\{\begin{array}{c}0 ; x \leq 600 \\ \frac{x-600}{50} ; 600 \leq x \leq 650 \\ 1 ; x \geq 650\end{array}\right.$

2. Himpunan fuzzy Tes Kompetensi Akademik (TKA)

Berikut untuk himpunan fuzzy Tes Kompetensi Akademik (TKA) :

Tabel 2. Himpunan fuzzy Tes Kompetensi Akademik (TKA)

\begin{tabular}{|c|c|c|}
\hline No & Nilai & Status \\
\hline 1 & $0-500$ & Kurang \\
\hline 2 & $500-600$ & Cukup \\
\hline 3 & $600-1000$ & Baik \\
\hline
\end{tabular}

A Membership Function Editor: Fuzzy $\quad-\quad \square \quad \times$ File Edit View

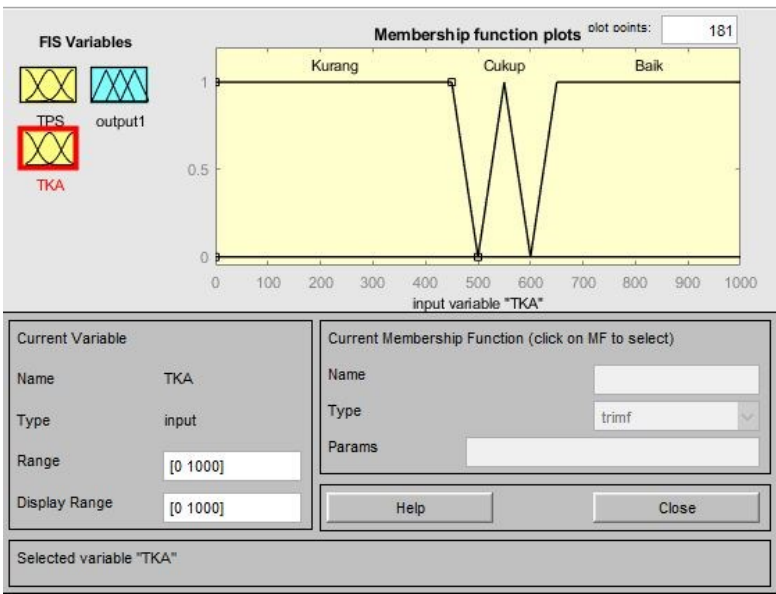

Gambar 7. Permodelan Tes TKA

$\mu$ Kurang $\left(x=\left\{\begin{array}{c}1 ; x \leq 450 \\ \frac{500-x}{50} ; 450 \leq x \leq 500 \\ 0 ; x \geq 500\end{array}\right.\right.$

$\mu$ Cukup $(x)=\left\{\begin{array}{l}1 ; x \leq 450 \text { atau } x \geq 600 \\ \frac{x-500}{50} ; 500 \leq x \leq 550 \\ \frac{600-x}{50} ; 550 \leq x \leq 600\end{array}\right.$

$\mu$ Baik $(x)=\left\{\begin{array}{c}0 ; x \leq 600 \\ \frac{x-600}{50} ; 600 \leq x \leq 650 \\ 1 ; x \geq 650\end{array}\right.$

3. Himpunan fuzzy Output

Berikut tabel himpunan fuzzy output :

Tabel 3. Himpunan fuzzy Output

\begin{tabular}{|c|c|c|}
\hline No & Nilai & Status \\
\hline 1 & $0-500$ & Ditolak \\
\hline 2 & $450-600$ & Dipertimbangkan \\
\hline 3 & $550-1000$ & Diterima \\
\hline
\end{tabular}




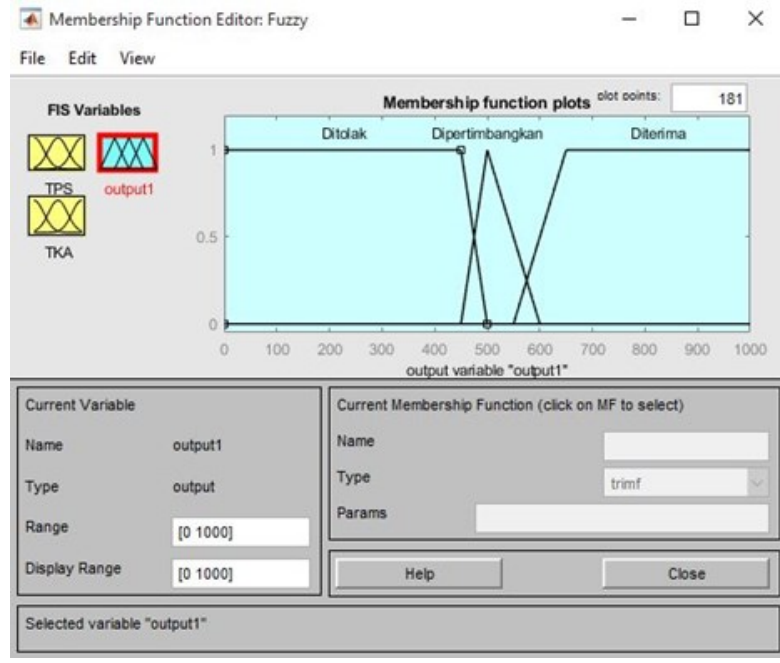

Gambar 8.Pemodelan Output

\section{Nilai Variabel}

Nilai dari variabel yang digunakan pada penelitian in yaitu: nilai Tes potensi Skolastik (TPS) = 537 dan nilai Tes Potensi Akademik (TPA) $=559$.

\section{Aplikasi Fungsi Implikasi}

Setelah himpunan fuzzy dibentuk maka proses selanjutnya adalah dilakukannya aplikasi fungsi implikasi.

Tes Potensi Skloastik $=537$, sesuai dengan himpunan fuzzy, nilai TPS masuk ke dalam kategori cukup (2).

$$
\mu C u k u p(537)=\frac{597-500}{50}=0,74
$$

Tes Kompetensi Akademik = 559, sesuai dengan himpunan fuzzy, nilai TPA masuk ke dalam kategori baik (6).

$$
\mu \operatorname{Baik}(x)=0
$$

\section{Komposisi Aturan}

Komposisi yang dibuat (rule) ada 9 rule, seperti gambar berikut :

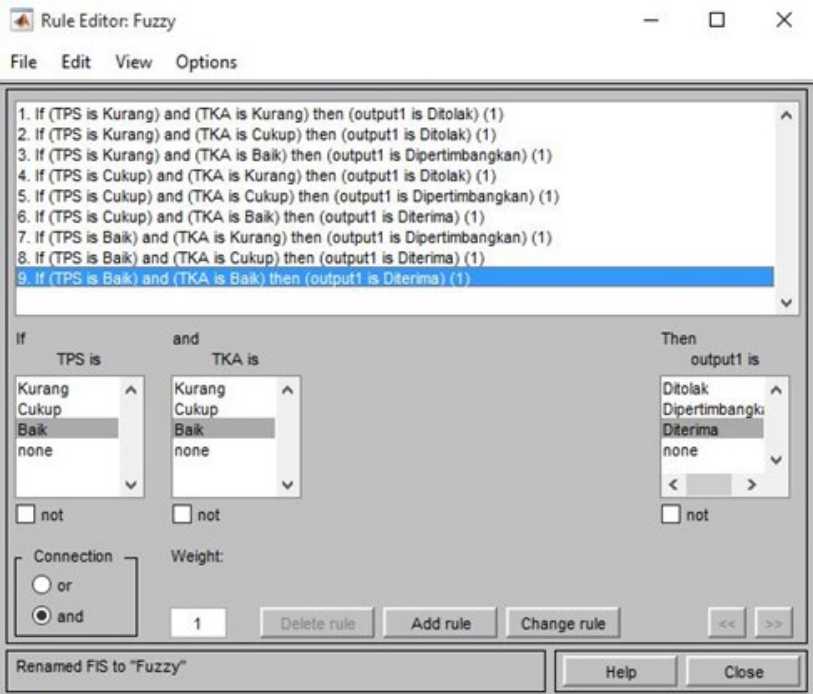

Gambar 9. Komposisi Aturan

\section{Defuzzifikasi}

$$
Z=\frac{597 \cdot 0,74+559.0}{0,74+0}=537
$$

Hasil diatas sesuai range yang ditentukan untuk output (tabel 3) dan rule pada gambar 5, yaitu dipertimbangkan.

\section{KESIMPULAN}

Dari hasil penelitian ini dapat disimpulkan bahwa logika fuzzy dapat digunakan sebagai alternative untuk mempermudah dan mempercepat proses seleksi penerimaan calon mahasiswa baru dibuktikan dari hasil simulasi pemodelan sistem penerimaan mahasiswa baru menunjukkan hasil bahwa nilai variabel dari Test Potensi Skolastik (TPS) dan Tes Kompetensi Akademik (TKA) sangat berpengaruh pada hasil output yang didapat dimana jika pada nilai kedua variabel tersebut lebih besar maka akan mendapat hasil output diterima begitu juga untuk hasil output dipertimbangkan dan ditolak tergantung dari besaran nilai yang digunakan pada kedua variabel tersebut. 


\section{DAFTAR PUSTAKA}

[1] M. A. Adiguna, A. Muhajirin, U. Pamulang, U. Bhayangkara, J. Raya, and P. M. Dosen, "Penerapan Logika Fuzzy Pada Penilaian Mutu Dosen Terhadap Tri Dharma Perguruan Tinggi," vol. 2, no. 1, pp. 16-19, 2017.

[2] J. Pareza, Alam, "Prototype Logika Fuzzy Inference Sistem Penentuan Status Gizi Berdasarkan Indeks Masa Tubuh (IMH) Menggunakan Metode Mamdani," J. IIm. Media Sisfo, pp. 421 - 434, 2017.

[3] I. K. E. R. Djara, T. Widiastuti, D. M. Sihotang, J. I. Komputer, U. N. Cendana, and M. Mamdani, "PENERAPAN LOGIKA FUZZY MENGGUNAKAN METODE MAMDANI DALAM OPTIMASI PERMINTAAN OBAT," vol. 7, no. 2, pp. 157 161, 2019, doi: 10.35508/jicon.v7i2.1645.
[4] R. R. Hafidzilhaj Harys, Imam Suprayogi, “APLIKASI LOGIKA FUZZY UNTUK PREDIKSI KEJADIAN HUJAN (Studi Kasus: Sub DAS Siak Hulu)," c, vol. 1, no. 1, 2014.

[5] P. Bidang, K. Sains, and W. Buana, “Jurnal Edik Informatika Penerapan Fuzzy Mamdani Untuk Sistem Pendukung Keputusan Pemilihan Telepon Seluler Jurnal Edik Informatika," J. Edik Inform., 2017.

[6] F. Ugm and F. Ugm, "Implementasi Metode Fuzzy-Mamdani untuk Menentukan Jenis Ikan Konsumsi Air Tawar Berdasarkan Karakteristik Lahan Budidaya Perikanan," vol. 24, no. 1, pp. 29-38, 2014. 